\title{
Aeromonas veronii
}

National Cancer Institute

\section{Source}

National Cancer Institute. Aeromonas veronii. NCI Thesaurus. Code C86131.

A species of Gram negative, rod shaped bacteria assigned to the phylum Proteobacteria.

This bacteria is hemolytic, produces acid from sucrose, produces gas from glucose and produces indole and mannitol. A. veronii is an opportunistic pathogen, causing infection in immunocompromised individuals. 